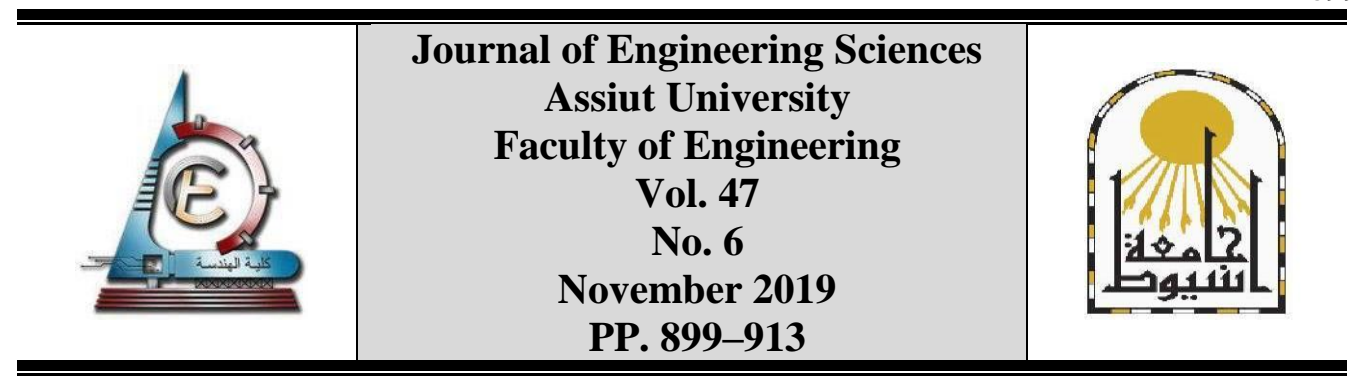

\title{
THE CONCEPT OF GREEN AREAS THROUGH VAROUIS HISTORICAL ERAS \\ A CASE STUDY FOR GREEN AREAS IN HERITAGE AREAS OF EGYPTIAN AND SAUDI ARABIAN COUNTRIES
}

\author{
Salma I. Dwidar ${ }^{1,}$, Walaa Metwaly ${ }^{2}$ \\ ${ }^{1,2}$ Architectural Engineering Department, Faculty of Engineering, Prince Sultan \\ University, Riyadh, KSA \\ ${ }^{1}$ Architecture Department, Faculty of Fine arts, Alexandria University, Alexandria, Egypt
}

Received 26 June 2019; Accepted 10 July 2019

\begin{abstract}
People have been interested in green areas for many years due to its strong correlation between human life on the earth and plant life, as green areas were a source of the beginning stages of agriculture, then stability, and then the formation of society. Moreover, green areas have been linked through the various eras with religious beliefs, engaged with ritual and worship, as well as social and cultural elements in ancient civilisations, including eastern civilisations, where they were symbols of paradise in Islamic civilisations. However, there has been an absence of green areas in urban areas, which, over time, has seen an increase in pollution. Therefore, creating urban green areas has become an important goal to achieve ecological balance and to meet the recreational needs for citizens. This research paper aims to recognise landscape design through a variety of historical eras, identifying the historical background and its importance in the urban space, as well as the foundations and theories of landscape design in architecture and urban spaces to meet the physical, spiritual, and psychological human need to preserve essential natural resources, such as air, plants, water, and wildlife. It also aims to promote economic development and activate social relationships, considering the allocation of open spaces in cities with the principles and planning designs suited to local conditions. The research will focus on the following points: [1] the importance of the concept of green areas design, [2] green areas through different ears, [3] the principles and planning design for green areas in architectural and urban spaces, and [4] analytical studies of green area cases in architectural and urban heritage areas of Egyptian and Saudi Arabian Countries.
\end{abstract}

Keywords: Theories of landscape, History of landscape, Green area, urban heritage area, Architecture Spaces, Principles and planning design

\section{Introduction}

Green areas are vital elements in city planning and at different levels, especially in heritage projects and places. They act as lungs in the human body through its role in sustaining people and the environment. The green area is a dynamic urban component with various dimensions and considerations that require special standards and design processes to ensure the social and cultural efficiency of the green service. 


\subsection{The Research problem}

Although green areas have played an important role in achieving environmental balance to meet the recreational needs of different projects, especially in the green areas of the heritage areas at the present time, there is an absence of concrete concepts for green planning in large cities. Especially with increasing pollution, the importance for green areas has emerged, along with its potential influence on architecture.

\subsection{The purpose of the research}

Suggest the criteria and principles of the design and planning process for green areas in urban areas and architectural spaces to meet the physical and spiritual heritage human needs in major cities, as well as maintain natural resources, such as air, plants, water, and wildlife.

Moreover, this study hopes to contribute to economic development and strengthening social relationships, while also considering the allocation of open spaces when re-planning the heritage areas in urban areas to suit the local conditions.

\subsection{Research methodology}

To achieve the research goals, we consider three important approaches:

First: Discuss theoretical approach to identify the concepts and functions of green areas, as well as the historical background of the existing green surfaces,

Second: Suggest criteria and guidelines from the theoretical backgrounds, which will influence the green area design stages that are suitable for the heritage areas, and

Third: Apply an analytical approach, including a comparative analytical study of green areas in architectural and urban spaces using two case studies in the Arab Republic of Egypt and the Kingdom of Saudi Arabia. This is based on the criteria and guidelines derived from the theoretical studies of the concepts and functions of green fields, along with historical studies, areas.

\section{The concept and functions of green areas}

Each of the general concepts of green areas and their main functions will be addressed in terms of their urban, environmental, community, and economic impact.

\subsection{The concept of green areas}

Green areas can be defined from the British as: "Large closed areas of land, usually made up of grass and trees, are designed to provide open spaces for recreation and health and general taste" [11] Green areas are the product of both nature and artificially man-made open spaces design. They include many recreational and sport activities, provide some services for recreation and entitlements, separate buildings to provide the light and ventilation, as well as create breathing space for urban communities. Especially for children, these green areas can be and are identified as specialised gardens with plants, fish, animals, etc.

\subsection{Green area functionality}

Green areas have an important function in urban, social, environmental, and economic levels. This importance can be explained as follows:

\subsubsection{The functions of green areas}

Green areas are an essential element in the urban planning of any city, and they are considered vital to positive impacts on human life through their functional roles; defining 
the cities and residential areas, separating various facilities, coordinating fields and other spaces within the urban community, as well as beautifying the cities, streets, and fields. Moreover, green areas provide space with a host of activities, depending on the needs of the users, such as activities for children's play, swimming pools, sitting and talking areas, hiking, relaxing and enjoying nature, among others. [1]

\subsubsection{The environmental functions of green areas}

Green areas play an important role in the environment, especially with recent technological progress. These areas combat the dangers of the mechanical civilisation and pollution of the city by [1] improving and reducing extreme climatic conditions by increasing thermal stability, which reduces the high temperatures of the summer and direct solar radiation. Green areas also provide shading and prevents temperatures from sharply falling in the winter; and [2] green areas compensate for the lack of moisture in the atmosphere, especially in dry hot areas, and also resist the air pollutants from gases and ozone-depleting substances.



Fig. 1. The green area fights the dangers of the mechanical civilisation and pollution of the city

\subsubsection{The social functions of green areas}

Green areas play a positive and effective role in a human's development as a result of the social relationships between the users of the urban spaces. These spaces allow for easy and simple social relationships, which encourage social equality and achieving a psychological and physical balance for users. It also provides fresh air and landscape areas, as well as reducing the pressures of work and improving the general health of the population. Most the studies have proven that green areas are an entrance to calm, self-confidence, and call for optimism.

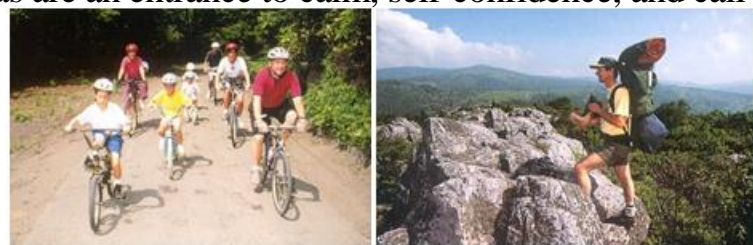

Fig. 2, 3. The green is providing many social activities for its users

\subsubsection{Economical functions of green areas}

Green areas play a primary role in economic development by contributing to the restoration of environmental balance at a lowest cost. This contribution raising the national income and restricts the state budget. The returns from the administration of green areas, especially on holidays and vacations due to the number of visitors searching for entertainment can increase the state budget. In addition, green areas contribute to the reduction of waste and radioactive materials.

\section{Landscapes designs through various historical eras}

The main objective of landscape design is to express the present to influence the future without neglecting the past. Green area design should reflect the cultural and social heritage of each society, where the concept of the green area is a reflection of the ideas in a particular period to reflect the views of the specialists in the field, which it can be characterised by periods with unique characteristics of the design as follows: 


\subsection{Gardens in antiquity}

The landscape spaces will be highlighted since the Pharaonic and modern times. These include many human civilisations characterised by garden design:

\subsubsection{Landscape design in ancient egyptian civilisation}

Gardens were much cherished in Ancient Egypt. The concept of landscape design was primarily for religious or ideological purposes, or for beautifying temples and cemeteries, as well as royal palaces. Their gardens were symmetrical in style, with straight lines and existing angles. Entrances were adorned with planted trees to show the movement from the entrance to the garden (13)


Fig. 4. The wall picture of the god Amun in |Karnak

Fig. 5. The Tomb of Nebamun, Thebes, 18th Dynasty:

Rectangular fishpond with ducks and lotus planted round with date palms and fruit trees.

\subsubsection{The landscape design of the Greek civilisation}

Due to the pressure of life and its growth, the landscape design in Greece was no more than accommodating their art and craftsmanship, without consideration of aesthetic factors, which confirms their lack of awareness for their urban design space, hence, the green areas became a place for political gathering [13], then a commercial centre, and then an official centre. Therefore, the Greeks didn't feel an urban vacuum that needed green areas.

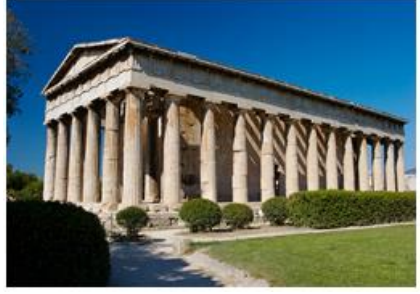

Fig. 6. Temple of Hephaestus, Athens

\subsubsection{Landscape design in Roman civilisation}

The landscape was re-designed for daily use and exploitation by the public, and all activities were transferred to the green areas. The Romans considered their spaces as design of formation and organisation. Their spaces were characterised by successful spatial relationships, as well as the principle of system and logic on the gardens' design, which was characterised by homogeneity and arrangement. Therefore, they introduced the "scale" in their designs, which are opposite axes (the average axis of each building perpendicular to another axis) [10].

\subsubsection{The landscape design in Islamic civilisation}

The Islamic landscape design was based on the principles and legislations of Islam, which effected urban solutions during that time. The city reflected the political system and social thought; therefore, green areas were characterised by privacy and reservations built in the middle of homes, surrounded by high walls, and were designed with geometric patterns and symmetrical garden with square or rectangular shapes. The roads ran perpendicular, and the floors were covered with coloured tiles, all to achieve the privacy of the population [3]. 


\subsection{Landscape design in the middle ages}

The purpose of the landscape in this era, due to war, was to serve a functional purpose. Gardens for entertainment and adornment were and replaced with vegetable and fruit gardens. By the end of the Middle Ages and after the return of political and social stability, gardens areas expanded and some were attached to castles. Green areas were carefully in designed for entertainment, as well as function [13].
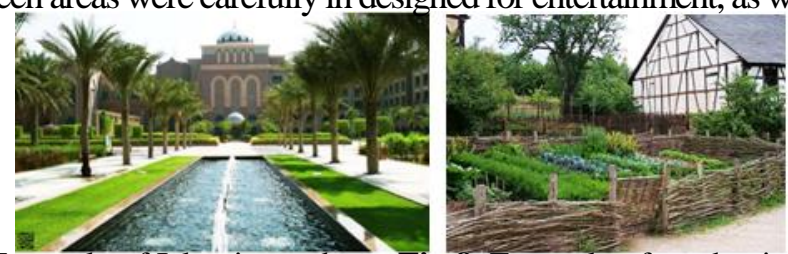

Fig. 7. Example of Islamic garden Fig.8. Example of garden in middle ages

\subsection{Gardens during the renaissance}

This period includes Italian and French gardens.

\subsubsection{The Italian gardens}

The main purpose of Italian gardens was for religious purposes; the gardens were placed on uneven hills, so they appeared as terraces and/or roads that included stairs or sloping paths, which suggested horizontal and vertical contact between different levels. The planted trees on both sides of the streets were designed to provide shade and reduce the intensity of the summer heat. The gardens were designed in a geometric style and divided into royal and public parks.



Fig. 9 Example of Italian garden-- Garzoni Villa

\subsubsection{The French gardens}

The main design concept of the French gardens was to reflect the nature of the aristocratic rules. The green areas were characterised with a symmetrical axis of proportion and an infinite perspective that reflected the wealth and social structure of France, as well as the creation of the principle of human control over nature. Also, gardens were characterised with large fountains and statues, with the benefit of the surrounding landscape. [8]



Figure 10: Example of French garden-- Versailles Garden

\subsection{Gardens in the Modern age [14], [15]}

These ages include the English, American, and Japanese gardens.

\subsubsection{The English garden}

During this time of democratic governance, in which all human beings in the community are respected, the garden design is based on the harmony of architectural elements and nature. Its 
purpose is to establish social parks for all the members of society. The spaces have been replaced by gardens, which may extend to cliffs covered with grass and scattered trees. Moreover, the lakes have been returned to their natural form, across which, bridges have been built.

\subsubsection{The American garden}

In the early 20th century, the American park was connected to the home and designed to provide suitable space for use as a garden, and to make good use of the sun, wind, and scenery. The garden design was characterised by a free design and highlighted the art of modern colouring and interesting sculptures and statues. In addition, the designs used the possibilities of the site, free from the constraints of engineering styles to meet the requirements of users, along with the appropriate use of the locations. [9]

\subsubsection{Japanese gardens}

The purpose of the Japanese garden is to provide a quiet place for meditation and is often connected to religious complexes, where they believe man is free. Nature is also stable and contains some basic elements, such as water and rocks (lakes and mountains), along with a few architectural elements in the garden. Gardens are classified as rock gardens, tree gardens, tea gardens, and dry gardens. [7]



Fig. 11. Example of a Japanese Garden

\section{The principles and criteria affecting the design of green areas}

Discussing the influence of human factors (non-physical) and environmental (physical) on the urban and architectural design of the green areas, which are divided into design considerations and the function and the range of aesthetic and symbolic and security leads to the idea of design, will be addressed these principles and standards in detail as follows.

These principles and Criteria can be divided into four sections that have been derived from the concepts and functions of the green areas and the historical analysis.

\subsection{The principles and criteria that affect the design of green areas}

Human and environmental (physical) factors impact the urban design and architecture of green areas considering function and the aesthetics. Diagram (1)



Diagram 1: for the design consideration of green areas 
Salma I. Dwidar, Walaa Metwaly, the concept of green areas through varouis historical eras

\subsubsection{The fundamental and human standards divided into social and cultural criteria}

The social and cultural factors that affect users are their individual numbers, preferences, needs, customs, traditions, their anticipated use and enjoyment of the space, the social relationships established there, and their potential desire to preserve and enhance its scope. Therefore, the designer should achieve some kind of compromise between the user and the place by creating an environment that enables them to express themselves. [5]

Economic Factors: This is one of the main influences on the design process, which reflects on the design of the green areas. Economic considerations are meant to meet the requirements of available resources with the best selection and quality of these resources and with an aim toward the users. [12]

Administrative Factors: Administrative organisations are responsible for these standards and control the political and regulatory decisions from one country to another.

\subsubsection{Environmental and physical standards}

\section{Non-Living Natural Determinants:}

Climate: This is one of the main considerations that govern the design of green areas. Climate information is available for a specific location with a series of data related to temperature, humidity, wind speed, direction, movement of the sun, shade, and lighting, which effects which plants are selected to fit with the prevailing atmosphere on the site and to achieve the functional and aesthetic aspects.

Location: The site analysis is of great importance for issues of access, along with consideration to its advantages and disadvantages and its surroundings to achieve the best geographical location.

Soil: is one of the basic factors that must be considered to determine the suitability of the green aresfor the selection of suitable plants, as well as appropriate irrigation methods.

\section{Natural Living Determinants:}

It is the green vegetation's cover that is a source of the oxygen necessary for human life. It is also influential in the design process.

\subsubsection{Design Considerations for Green areas \\ The Conceptual Design Considerations:}

This idea must be a clear and appropriate for the user's needs. It should be designed based on each unique environmental, and therefore, the designer can generate unique and nontraditional ideas that are compatible with the nature of the site and within the desired goals.

\section{The Functional Considerations:}

To achieve the successful design idea, it is necessary to choose the successful functions of the green areas and the use of the design elements for human comfort and service with economical exploitation of green areas, and propose a network of roads that link the functions and uses within the site, as well as externally to regulate the movement of the people from one space to another.

The Aesthetics Considerations:

The design must be successful for the green areas to achieve psychological pleasure and comfort for the users, by relying on art and other special determinants of the composition, according to the designer's ideas on how to achieve a balance of, unity and diversity, and the main axes. 


\section{Security Considerations:}

To protect users during their visit to the green areas, the uses of finishing materials and safe treatments for children and adults, along with protection against accidents and fire hazards, such as security devices, instructions on how to quickly evacuate the area, and periodic maintenance on electrical devices, cables, and alarms.

\subsection{The stages and the process of designing green areas}

The design process is an integrated approach which is divided into: Diagram (2)

- Identification of problems that depend on human needs in the region to be designed.

- Determine the goals to achieve the designer's view based on the problems, and how define appropriate solutions, and choose an alternative design.

- Analyse the information (non-physical) based on the previous criteria and standards that have a direct impact on the design development and based on human needs and the physical aspects of the green areas.

- Determining the function of the green areas and their architectural characteristics according to the previous guidance standards.

- Propose alternative designs that determine the future needs of the green areas by standard rates, development rates, and future needs.

- Choose the best alternative design idea which aims to meet the needs and desires of current and future users.

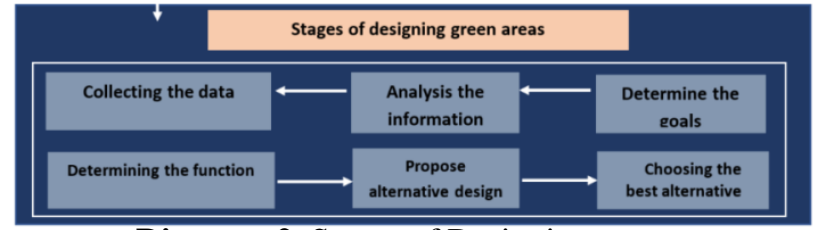

Diagram 2. Stages of Designing green areas

\subsection{Implementation, sustainability, follow-up, and maintenance}

The designer should follow the stages of implementation for the green areas to ensure the correct implementation of the design idea and follow-up with implementation results, and consult the feedback from the information used when returning to the planning cycle. Follow-up and maintenance play important roles in preserving the green areas and completing the design through the programme development to maintain the area with all its physical and natural components.

The designer should propose a programme for cooperation between the administration and the users. This programme includes:

- Regularly scheduled maintenance should be performed along with the capacity for urgent maintenance when necessary. Funds must be provided for suitable maintenance and follow-up

- It is essential to maintain the character of the place during maintenance and development.

- Balance between the presences of controlling the green areas with the freedom to enjoy the space, along with provisions for safety of green areas.

\subsection{The evaluation stages of designing green areas}

The level of green areas should be evaluated through different periods of time in terms of achieving the requirements of the users and their needs, as well as evaluating the level of sustainability, follow-up and maintenance of spaces, and maintain the design. 
Salma I. Dwidar, Walaa Metwaly, the concept of green areas through varouis historical eras

\section{Analytical studies of green area in selected case studies in the Arab Republic of Egypt and Saudi Arabia}

This study will analyse and evaluate the selected case studies of the green areas using the Previous Crateria that have been drawn from the theoretical and historical information to move from the stage of philosophy to a viable manner.

Finally, the study concludes with the recommendations that can be applied to future green area designs, especially in a heritage area.

\subsection{Analytical study of a green area in a historical area of the Arab Republic of Egypt}

Many studies have confirmed that the percentage of green areas for the population in Cairo is $0.16 \mathrm{~m}$ 2/person, and there are almost no green areas, which confirm the need for them in Cairo, especially in the historical areas. [2]

\subsubsection{Al-Azhar Park Project: reasons for selecting this location, its origins, and location}

Al-Azhar Park is the largest green area in Cairo, established a century ago. It represents a major transformation in Egyptian parks. It is also the largest park in North Africa and the Middle East. The park was built on an area of 30 hectares by the Imam in the Islamic community of Karim Shah al-Husseini (Agha Khan IV), after he decided to provide a garden to Cairo City in 1984. This decision was taken up during the 1984 conference, "Developing Capital: for Keeping Pace with Cairo's Civil Growth" and the project, "Support for Historic Cities of the Aga Khan Foundation for Culture" [6] The site was chosen on a high hill which overlooks a panoramic view historical Cairo, that is bordered on the west by the ancient city of Fatimid, on the south by the Sultan Hassan Mosque and Qaitbay Castle, and on the east the, tombs of the dead.

\subsubsection{The analytical study of Al-Azhar Park}

The following is a presentation of the analytical studies of the garden through the preproject phase, identification of problems, objectives, information analysis based on the guiding criteria (social-physical and environmental) in the design stages, the post-design stages of following-up, maintenance, and evaluation.
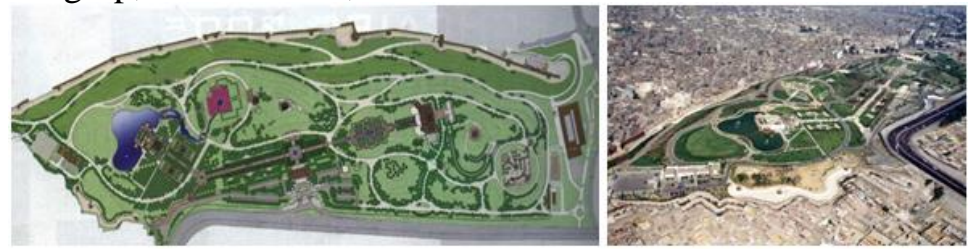

Figs. 12 \& 13. A general aerial photograph and plan for AL-Azhar Park, Cairo Egypt


Figs. 14 \& 15. Pictures of ÂL-Azhar Park, Cairo, Egypt

\section{Analytical Studies for Pre-Design}

Identification of the problems: The area is crowded with many buildings and no green space. The area that has been chosen was the main garbage dump of Cairo City for 
centuries, located alongside burial sites. These areas are considered uninhabitable and are not normally frequented by citizens.

The Project Objectives: The design aims to create a special park for the people of the region who lack green areas, with a diversity of functional green designs and plants. It is based on the exploitation of both the nature of the site, its topography, and the historical scenes that it overlooks.

Information Analysis: The information was collected based on guiding criteria: (humanitarian-physical, environmental-non-humanitarian aspects).

Social and Cultural Aspects: The design considers the need for green areas and activities for recreation and social communication, along with safe play for the children.

Economic Aspects: The financial coverage of the project was donated by the Imam of the Islamic community, Karim Shah al-Husseini (Agha Khan IV).

Administrative and Operational Aspects: The project's owner has become part of the "Historic Cities Support Programme of the Aga Khan Foundation for Culture" and has followed its administrative laws.

Environmental Aspects (Physical): Climate: The climate there is a moderately hot, dry climate in the summer and warm in the winter.

Location: The project has faced many operational and technical challenges. The site of the project was a place where waste was buried for 500 years, thus, it required the proper digging, settling, and filling of 765,000 m3 of soil. Much soil was replaced with new soil, a special kind of sand and soil that allows for the cultivation of a variety of plants.

Soil: The project used the best soil to allow the growth of any type of plants.

Plants: Through many tests conducted on the soil at the site, it has been shown that some suitable plants and trees in the garden will be able to survive in these climatic conditions and horticultural areas in the centre of the garden.

\section{The Design Phase:}

Project Designer: Cates International, Dr. Maher Satino, Dr. Laila El Masry

The Design Concept: The design of the garden was inspired from traditional Islamic garden styles during the historical periods and from different areas of the Islamic world. The concept of the design was based on the organisation of different areas in the traditional garden style, the shaded seating areas and the Fatimid-covered roads also used in the garden buildings. In addition, the Persian and Indian elements are reflected in the water elements' formations, through a series of fountains, basins and lakes. The design also depends on the main axis (Kasaba), which links the entire garden from north to south.

Project's Description: The project can be described by:

The main axis of the width of eight metres for two sides of rows of royal palms and waterfalls that leads to the castle in the south.

The main axis directed towards the minarets of the old city, leading to a small lake on the lower plateau of the site.

The axis toward the restaurant on the lake which characterised by a panoramic view of the monuments. 
The buildings in the garden are from the Rabwa Restaurant, a symmetrical design around the North Axis that passes through an open entrance and can be reached through the main entrance of the Park and the cafe designed to float on a lake which gives a different sense to the visitors

\section{Post-Design Phase:}

Project Implementation: Responsible for the implementation is a subsidiary of the Aga Khan institution.

Management, Maintenance, and Follow-Up: A subsidiary of the Aga Khan Company management and maintenance of Al-Azhar Park (self-sufficiency), which takes advantage of the restaurant, and coffee, shops and entrance fees for visitors.

Drainage and Maintenance: Many of the losses that occur frequently of visitors in the park, which may make the burden is great on cost-saving and maintenance.

The Construction: Construction of Al-Azhar Park has been highly regarding for social and economic development by improving the quality of life there. The park location is considered as the best location to view Cairo's historical buildings. In addition, Azhar park is the biggest place for attraction the residents of Cairo and foreign tourists where the area that was originally neglected garden and also is considered as the largest green area in Cairo inches of a century.

5.2. The analytical studies of one of the green areas in the Kingdom of Saudi Arabia in historical area

The Supreme Commission of Riyadh Development sought to integrate the natural and urban environment by undertaking several projects to contribute the restoring of balance between the building and the open spaces and also between the urban and natural environment.

5.2.1. The reasons for selection of Salam park and lake project as an analytical study, its origin and location

One of the contributions made by the Supreme Commission of Riyadh Development is to achieve the balance of the city, which was established on an area of 253.000 metres 2

This park was chosen to be located in a populated area close to a heritage area and near to the Qasr al-Hakam and the Great Mosque, it was founded in 80 years in $1360 \mathrm{AH}$. The land of the park is a former Salam farm, which is characterised by the fruits of palm trees, their natural composition and it is located in the middle of residential

\section{$\underline{\text { Social and Cultural Aspects }}$}

\subsubsection{The analytical study of Salam Park}

The following is the presentation of the analytical studies of the park through: the preproject phase, identification of problems, objectives, information analysis based on the guiding criteria (social - physical, environmental) in the design stages, the post-design stages of following-up, maintenance and evaluation
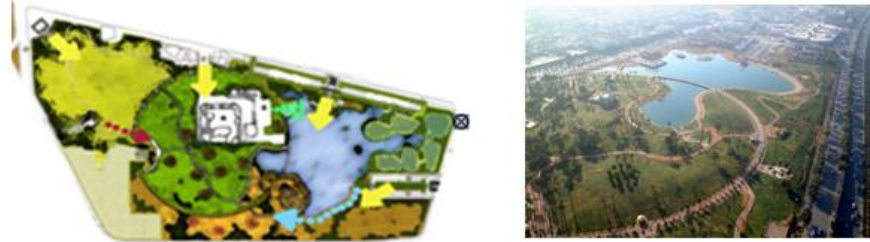

Figs. 16 \& 17. A general aerial photograph and plan for Salam Park, Riyadh, KSA 




First: Analytical Studies for Pre-design

Identify Problems: The main problem is the lack of a residential area near to the heritage area and the green areas where most of the houses are closed because of the concern for family privacy.

The Project's Objectives: Provide suitable open spaces for the general uses of public, provide support services for activities and recreational uses, obtain a well-thought-out design in harmony that suites with the local environment in Saudi Arabia, focus on educational value, highlight the elements of local heritage and culture, and integrate the green areas with the built surrounding environment.

Information Analysis: Collection and analysis of information based on guiding criteria (humanitarian-physical, environmental-intangible).

\section{Humanitarian Aspects:}

- Social and cultural aspects: The need for green areas and activities for recreation and social communication has been reached.

- Children in the region need a safe some games.

- Economic aspects: The Supreme Commission for the development of Riyadh is responsible for economic aspects.

\section{Environmental Aspects (Physical):}

Climate: hot dry in summer, warm in winter.

Location: The land of the park is the former Salam farm, which is characterised by the fruits of palm trees and their natural composition in addition to some buildings overlapping natural configuration. The park is surrounded by a number of vital roads. The information centres are located on three streets from the north, Tariq ibn Ziyad, Al-Salam Street and the south from Asir Street. Most of these roads are used for commercial uses and mixed with residential uses.

The main problems of the site are water feeding but the General Authority of Riyadh area linked the park with a network of land treatment plants for the water of a thousand water wells used only to irrigate crops.

Soil: The soil is good as it was the land of the farm and before being converted into a park

The plants include the rest of the fruits palm trees, also a new palm tree has been added, bringing the total palm tree to 1250 palms, and green grass which covering the hills with the park.

Second: Design Phase:

Project's Designer: The Supreme Commission for the Development of Riyadh City has called for an international competition to design the gardens of Al-Salam Park. The project which won the first prize was presented by the Office of the Urban Studies House.

The Project Idea: it is based on the creation of a multi-family park environment that serves its visitors to spend enjoyable times by providing the park with green areas, the needs of public facilities and children's playgrounds, and the creation of an optical 
environment of natural formations that will reduce the urbanisation and traffic density in the area. Therefore, the idea of the project included the following:

Taking advantage of the strategic location of the park, which is located in the heart of Riyadh and overlaps with the most important axes of movement (King Fahad Road), take advantage of the large space by finding a place that goes beyond the issue of traditional recreation to connect the population history and culture, also provide different types of gardens and open space, Taking advantage of the architectural and natural elements of the park, and integrating them with the rest of the services provided to visitors, including the historic mosque, the fruitful palm trees and green hills.

Project Description: the project has three main entrances, the main entrance from the south side leading to the lake and the eastern stream leading to the pedestrian corridors and the side entrance coming from Asir Street. the project consists of four different environments.

Cultivated environment: Hills environment: The centre of the park was almost flat ground, but due to the excavation of the lake formed a range of hills spaced no more than 6 metres height is characterised by a simple slope to make it safe for pedestrians for all ages. The hills are covered with a green grass and palms.

The Lake Environment: it covers 34,000 square metres in the south of the park and includes a number of natural and mechanical structures that prevent water stagnation. Plants that limit the spread of harmful algae have also been planted and are a source of irrigation water for the entire park. It is an attractive place for visitors to the park.

The environmental area: located in the southeast of the park, it benefited from its low hill area and pockets extending from the lake, also it is essentially a nature reserve for various species of wildlife and therefore available to visit the public under the guidance of the park guides.

Third: The Post-Design Phase: Implementation of the management, maintenance and follow -up with the project: The Chamber of Commerce in Riyadh contributed 20 million riyals of the cost of the project to achieve the concept of integration of the public and private sectors for management, maintenance and is based on operation of the park one of the specialised institutions in the fields.

The construction of the Salam Lake and Park is a catalyst for overall social and economic development and improving the quality of life in the region. The park has achieved its main goal of interacting with the surrounding environment, unlike most of parks and green area that are usually separated from surrounding neighbourhoods. in addition to the sidewalks, which are broad security for pedestrians. The buildings inside it have been used to indicate the historical location that tries to connect with historical place in Riyadh with its inhabitants.

\section{Conclusions}

\subsection{Result}

1- A review of each concepts of the green areas and address the various functions of urban, social, economic, environmental and follow the historical development of the coordination of green areas throughout the historical ages.

2- Reach to the principles and standards which are divided into humanity and environmental standards on the urban and architectural design of the green areas through the considerations of design and function which lead to aesthetic. security, and the symbolic to the idea of design. 
3- The stages of the green design process is to integrate approach that divided into: Identification of problems, and objectives of the project, Determining the function of green areas based on the previous standards, the proposed design alternatives, which determine the future needs of green areas by standard rates, The development of the green areas, the future needs of the region, and the choice of the best alternative design concept and follow-up with stages of the implementation of green areas to verify the correct implementation of the idea of design, also maintenance have an important and essential role in maintaining green areas and the completion of design roles through a maintenance programme of the place and for all the physical and natural ingredients...

4-Conducting an analysis and evaluation of one of the selected models of green surfaces in the Arab Republic of Egypt and Saudi Arabia through the standards and criteria that were derived from the theoretical and historical background to be a complementary study of the research to move from the stage of philosophy to its preparation in a viable manner the end of the recommendations can be applied in the future on the design of green areas heritage areas.

\subsection{Recommendations}

1- In the design of green areas, it should be focus on the role of the green areas and the basic function for which it will be designed to, and understanding the environment of time and space to serve the human's needs and create a suitable environment for stability

2- Studying the needs and requirements of users in terms of social, cultural and physiological and follow - up change in these needs and compatibility with environmental conditions surrounding

3- Enact laws and legislation that prevent the infringement of green areas because of their importance to the environment and human

4- Focus on the plan development of the management and maintenance of the green space which includes tasks studied for the cooperation between the project's designer and management of the place in order to ensure its efficiency to be consistent with the designer's thinking and with the needs of users.

6- Emphasise the role of maintenance and follow-up in the development of green areas standards without changing in the basic concept of the green areas and the purpose for which it was built for by designer to complement the role of design.

7-Educate the young generations for the importance of the green areas from childhood, and participate the users in the maintenance of the green areas with money or effort in order to feel that it is private ownership through groups Work and volunteer teams to guide and awareness of the situation to promote it.

8- Focus on the green landscaping projects that contribute to the integration of the natural and urban environment, highlighting the elements of local heritage and culture and integration between the green areas and the surrounding built environment.

9- The green areas design can be derived from the design criteria and standards which have been derived from the theoretical and analytical studies as mentioned in the paper.

10- Encourage the role of the private sector for the green areas financing, which reduces the burden on the state and increases the chances of the green areas proportions.

\section{REFERENCES}

[1] Abdul Hamid Abdel Wahid, "Introduction to the design of green areas and environmental urban spaces of the urban environment in the cities" Dar Ghraib for printing, Cairo, 1988. 
[2] Aga Khan leaflets in the garden, Azhar Park, Cairo,Eygpt. 2005

[3] Broadbent, G., "Emerging Concept in Urban space Design", Van Nostrand Reinhold Company, New York, 1990.

[4] Elizabeth Barlow Rogers, 'Landscape Design', A Cultural and Architectural History, Harry N. Abrams, Inc., Publishers, Japan, 2001.

[5] Forti, August and Bisogno, Paolo (ed), '"Research and Human Needs', 181, p 11.

[6] High Commission for the development of Riyadh, Saudi Arabia.

[7] John Ormsbee Simonds, 'Landscape Architecture', A manual of site planning and design, McGraw-Hill, Third Edition, 1997.

[8] Lynch, K., 'Site Planning', MIT Press, Cambridge, 1975.

[9] Ministry of Housing, Utilities and Communities - General Authority for Urban Planning: "Project for the Study of Planning Services Rates and Criteria in Egypt" (Phase I Report).

[10] Rawia Hamouda, "External Spaces and their Relation to the Development of the Architectural Concept ", p. 129.

[11] Sablet, M.D "Des Escapes Urbains" Agreables Avivre, Deuxieme edition Editions du Moniteur, Paris, 1991, p 41.

[12] Schulz. C.N., 'Meaning in Western Architecture', studio vista Book, London, p 93.

[13]Zucker, P., "Town and Square, from the Agora o the village green", the MIT Massachusetts, London, 2003.

[14] Varotto,M., Bonardi,L., Tarolli,P. “ World terraced, Landscape: History, Environment, Quality Life.”, Springer Nature, Switzerland, 2019

[15] Montealegre, M. , Sánchez, "Urban Commerce and Protected Cultural Landscape" . MDPI. January 2019-pp.72-85

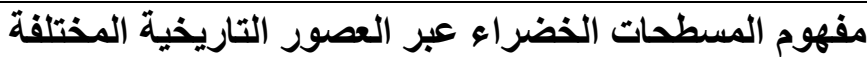



\section{ملخص البحث}

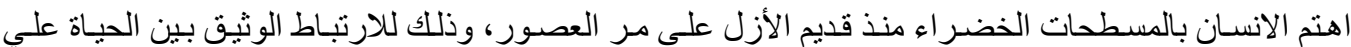



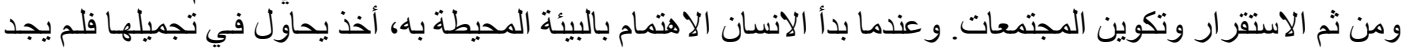

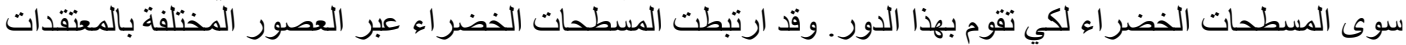

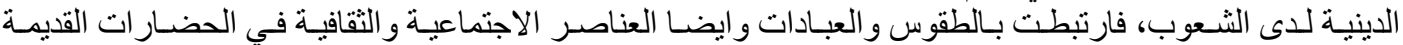

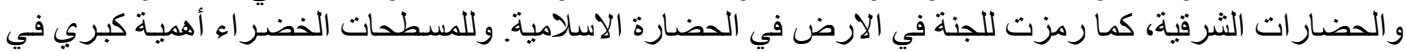

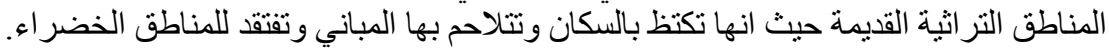

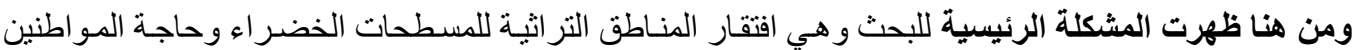

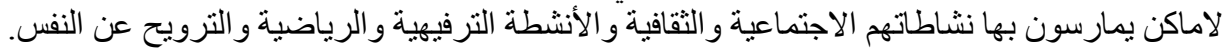

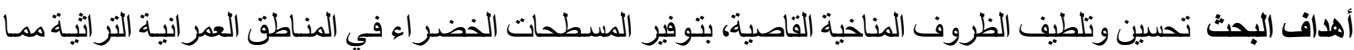

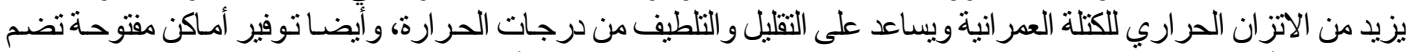
العديد من الأنشطة الترفيهية والرياضية وتقدم بعض الخدمات للموطنين تستعمل لأغر اض الترويح عن النفس و الاستجمام.





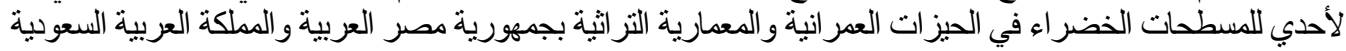

